\title{
Study on the Conservation Mode and Renewal Strategy of Ancient City of Anyang
}

\author{
Zhenzhen Wang, Yujie Lou, Benxiao Zhang \\ School of Literature and Law, Zhejiang Agricultural and Forestry University, Hangzhou, China \\ Email: wzz19950821wyyx@163.com
}

How to cite this paper: Wang, Z.Z., Lou, Y.J. and Zhang, B.X. (2020) Study on the Conservation Mode and Renewal Strategy of Ancient City of Anyang. World Journal of Engineering and Technology, 8, 92-103. https://doi.org/10.4236/wjet.2020.81009

Received: December 31, 2019

Accepted: February 17, 2020

Published: February 20, 2020

Copyright $\odot 2020$ by author(s) and Scientific Research Publishing Inc. This work is licensed under the Creative Commons Attribution International License (CC BY 4.0).

http://creativecommons.org/licenses/by/4.0/

\begin{abstract}
Anyang City, Henan Province, is one of the eight ancient capitals in China. After the change of history and the alternation of times, there are many kinds of ancient buildings and traditional houses in the ancient city. Combined with the current development of the ancient city, through the combination of actual research and questionnaire survey, clarify the current development problems, according to the principle of combining protection and renewal, put forward the feasibility of solving problems from the management concept and technology, and clarify the development direction of the ancient city.
\end{abstract}

\section{Keywords}

Ancient City of Anyang, Protection, Renewal

\section{Introduction}

In the current transformation of the old city, improper transformation will cause the destruction of historical and cultural heritage to varying degrees, and the historical characteristics of the ancient blocks and buildings preserved in history are gradually assimilated. In recent years, the development of the city and social progress inevitably affect the traditional style of the ancient city. In order to promote the prosperity of the urban economy and increase the capacity of the urban population, it is necessary to transform the streets and buildings of the ancient city. In recent years, Anyang City has made many useful attempts on the renewal and protection of the ancient city. But with the passage of time, some practices have no longer adapted to the current situation of the city. Subsequently, a series of new problems of the protection of the ancient city has emerged.

In the current urban construction of Anyang City, it is particularly important to coordinate the relationship between the protection and renewal of the ancient city, to deal with the symbiosis of the new city and the old city, and to solve the 
problem of economic development and the direction of the development of the ancient city [1]. The transformation and renewal of the ancient city of Anyang have certain universality and particularity [1], which can not only draw lessons from the reconstruction ideas of relevant cities; then use them according to their own conditions, but also innovate their own development model, which has far-reaching significance for the past, present and future. How to analyze the existing problems, study the direction of development and put forward the concrete countermeasures of protection and renewal according to the current actual situation is an important task at present and in a period of time in the future. The goal of the sustainable development city in our country is to build a modern city with proper layout, complete living facilities, giving consideration to both work and life, comfortable residential area, involving the overall quality of the city, use function, landscape sketches, urban culture and other aspects. In order to achieve this goal, it is necessary to formulate the corresponding planning scheme according to the development of the times and promote the sustainable, healthy and stable development of the city. Practice has proved that the development of planning theory in each period has formed a system with different characteristics and styles. In today's rich information, sustainable development theory and other theoretical methods provide more diverse reference objects for urban development and decision-making, but also a new challenge.

Looking at the ancient city protection studies abroad, there are studies on the protection and development of Pompeii ancient city. In the context of the archaeological sites of Castamonu and the data obtained from the studies in the neighboring areas, through the evaluation of research and literature, Cetin will show the problems and opportunities that may be encountered while maintaining the original characteristics of the area. This will ensure its protection, balance and sustainability, as well as landscape design and tourism development activities in the region [2].

\section{General Situation of Anyang Ancient City}

\subsection{Status of the Ancient City}

The buildings, pavilions, temples, pagodas and three-dimensional landscapes in the ancient city, such as Gaoge Temple, Wenfeng Pagoda, Drum Tower, Bell Tower and Chenghuangmiao, etc. Echoing each other from afar, form a harmonious urban spatial sequence. The Bell Tower and Drum Tower stand side by side across the street, Wenfeng Pagoda and Gaoge Temple are located in the west and east of the ancient city respectively, and Chenghuangmiao is in the center of the city. Most of the commercial streets in the city are ancient buildings, and the most prosperous commercial areas are on the North Street, followed by the West street, the east street and the south street. Ancient trees and ponds in the ancient city of water formed a unique landscape features, high and low buildings, the city scenery. The ancient city of the main building to $1-2$, the average number of 1.3 storeys. Some of the traditional houses and courtyards are 
still in the city, some of the traditional streets and alleys have been transformed, there are some to maintain the original appearance. Formed the current prosperity of the ancient city business, land value appreciation rapidly, traditional and modern architecture mixed situation (Figures 1-3).

\subsection{Characteristics of the Old Town}

The pattern of the distribution of the ancient city of Anyang can be summed up in a sentence, that is, the eighteen lanes and seventy-two alleys of Jiufu, with the North-South Street as the boundary, the mansion in the east and the lane in the west. Seventy-two alleys mainly refer to the small and medium-sized alleys of the city. There are also Longfeng Street and the eighteen Luohan Street branches, among which Longiie refers to Tianshuijing Street, mostly two, three and four courtyards, and the nine-door Haoting Courtyard is distributed in LongStreet, where two large households reside. LongStreet is named. Feng Street is a little inferior to Long Street, but the building structure and housing layout of the two streets are relatively neat, the overall appearance is more elegant. 18 Lohan Street is 18 Lohan like in the north and south streets on the east and west sides of the intersection to protect the city.

\subsection{Analysis of the Existing Problems of the Ancient City}

\subsubsection{Undue Demolition of Historical Blocks and Traditional Dwellings} In the 1990s, in order to develop the economy of the ancient city, the government carried out a large-scale renovation of the ancient city without scientific planning and evaluation. The current Wenfeng Middle Road was opened without authorization, and the ancient city was forced to be divided into two parts, and the north and south parts were separated forever. The traditional pattern of the ancient city was destroyed because the construction of the road had to demolish the buildings covering the area, and the traditional residential buildings and historical blocks had to make compromises. Overlooking the ancient city of

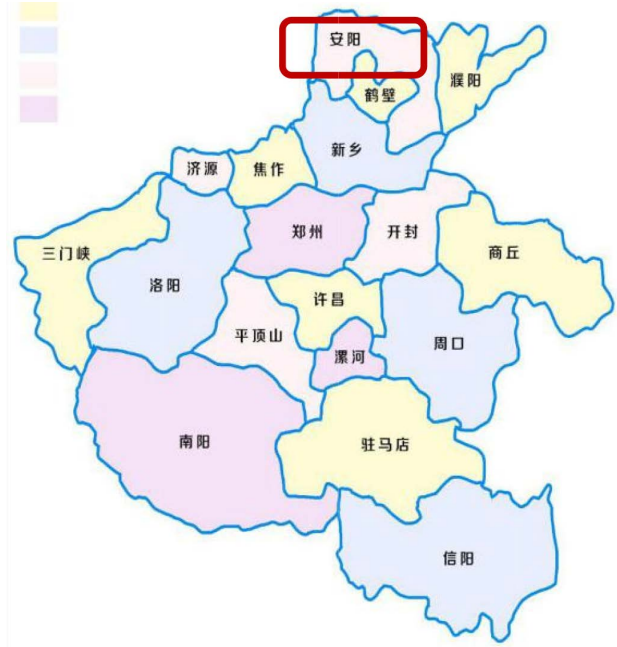

Figure 1. Geographical position. 


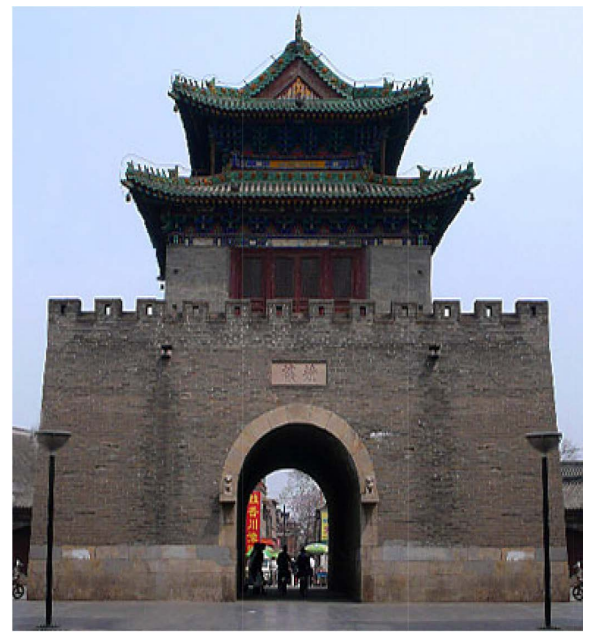

Figure 2. Bell tower.

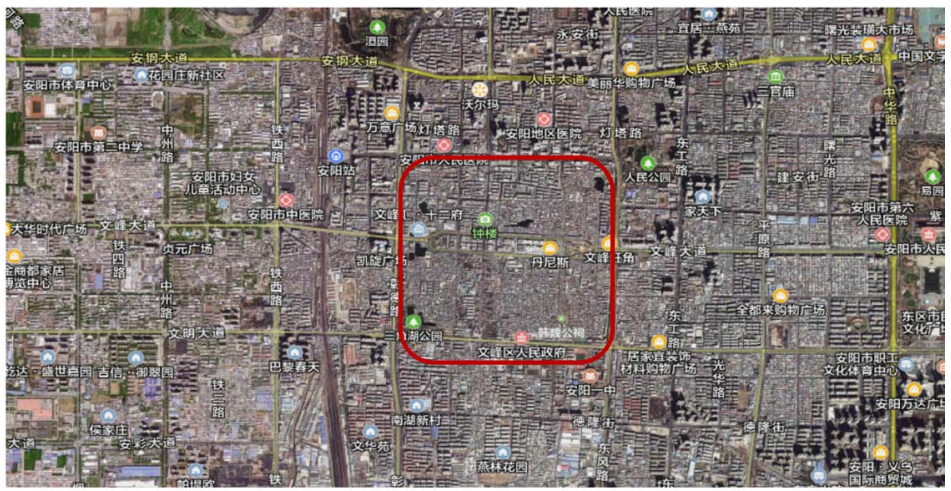

Figure 3. Location of the ancient city.

Anyang, Wenfeng Middle Road, which is composed of two one-way streets, seems very disharmonious, like two sharp swords passing through the city. Even if the opening of Wenfeng Middle Road brings new opportunities to the city's economy to a certain extent, it does more harm than good in the hearts of most people, which is not optimistic. The historical features of the ancient city emit unique historical charm after years of precipitation and cultural rendering, once destroyed, it cannot be restored. In addition to Wenfeng Road, Tangzi Lane, South Street are not spared. Reconstruction process destroyed part of the traditional quadrangles and ancient trees, heavy losses. After all, the times are to move forward, but reconstruction is not a simple depth of development, blind construction.

\subsubsection{Living Facilities in the Ancient City Can Not Meet People's Needs} The ancient city has been preserved for quite a long time. Considering the special geographical location of the ancient city and its key protection, it has not been able to enhance the living experience of the residents in the ancient city. The municipal facilities are not perfect, the roads are crowded and narrow, the old wires are pulled randomly, and the appearance is very unsightly. The old fa- 
cilities have great safety problems, and the old houses are dark, damp and poor lighting. Living facilities have not been updated as scheduled, the backward foundation limits the pursuit of a better life of the residents in the ancient city, some residents choose to move out, and some houses have been uninhabited for a long time.

\subsubsection{Disappearance of Traditional Street Style}

In recent years, the renewal of the ancient city has taken into account the original style of the ancient city, but there is a lack of dynamic renewal, and there is also a lack of overall protection concept. In order to develop the business along the street, we have to demolish the original courtyard and rebuild it into a new type of antique architecture, although the appearance is similar to the overall style, but there are still unsatisfactory places to study carefully, such as the form is relatively single, traditional charm is not there.

\subsubsection{Conflict between Traditional Architecture and Modern Function}

The traditional buildings in the ancient city of Anyang are mainly for residential functions, while the new commercial functions should find a compatible way to deal with each other and maintain harmonious coexistence with the traditional buildings. Shops, bars, hotels and so on need large rooms and deep, so the traditional buildings are not suitable for these functions, and have to be rebuilt. In the process of rebuilding, some new buildings are too abrupt, functional problems have been solved, but the overall pattern and style are not harmonious.

\section{The Mode of Ancient City Protection}

\subsection{Government Legislative Protection}

Government legislation is an important aspect of the protection of the ancient city of Anyang. The protection of the ancient city should follow the relevant laws and regulations. The Protection Planning Norms for Historic and Cultural Cities, the Law of the People's Republic of China on the Protection of Cultural Relics and the Law of the People's Republic of China on Urban Planning are the laws and regulations that must be followed in the protection and renewal of the ancient city. The government can combine these laws and regulations according to their different regional differences to form their own unique local administrative laws and regulations, so as to provide a basis for the future direction of urban development. The government is the authority of urban protection, through the formulation of a series of protection policies to guide the implementation, the people are concrete practitioners. The government should mobilize the enthusiasm of the people for the protection of the ancient city, strengthen publicity and guidance, so that the people take the protection of the ancient city as their inescapable responsibility. At the same time, the government should also formulate corresponding protection procedures and systems, so that the protection of the ancient city has legal protection, the maintenance of order. Establish a sound protection mechanism, clear guiding ideology, for the protection of the 
ancient city to provide a full range of security. Urban planning was originally as a government action, but social progress and democratic development so that more groups can participate in it, for urban planning suggestions and suggestions, from then on to the road of democracy. As a strategic planning of urban development, urban planning has great responsibilities and complex tasks in the construction objectives and management methods of the city. The relevant departments of the city planning of Anyang have formulated "The Protection Planning of the Historic and Cultural City of Anyang", which further explains the key protection areas and the protection scope of the ancient city, and on this basis formulates the protection scheme.

\subsection{Protection of Material Forms}

The existing physical form of the ancient city of Anyang mainly includes the context of the city pattern, spatial form, historical relics, etc. The key objects of the ancient city are mainly cultural relics, including Wenfeng Pagoda, Chenghuang Temple, Bell Tower, Drum Tower, etc. The historical streets and alleys such as Cangxiang Street, North Street and South Street should maintain their respective characteristics on the basis of maintaining the traditional style. A series of renovation work is the main reason for the spread of these monuments, the transformation of the pond water surface maintenance, ancient and famous trees set up a special protection area, attracted a large number of investors competing to go, to improve the overall economic environment of Anyang City.

The traditional architectural form, the historical and cultural blocks, the traditional street pattern and space form, the water surface of the pits and ponds, and the ancient and famous trees in the ancient city are all the marks of the urban civilization and the special symbols of the city. In view of the poor living environment in the ancient city, the transformation of the ancient city can not be limited because of protection, some uninhabited and lost historical value buildings can be demolished, public green space and open parks can be built, while increasing greening, it also beautifies the living environment, and has the effect of purifying the air, improving the basic living facilities of residents and improving the living quality. The protection form of traditional dwellings with historical value should be protected first and then transformed, and the protection content should involve every specific detail and highlight the key points.

\subsection{Protection of Cultural Forms}

Culture in the ancient city of Anyang is mainly reflected in a variety of traditional folk cultural activities, commercial activities and the daily life of residents. As one of the important ancient capital city, Anyang ancient city has rich cultural types. Historical city Anyang has many cultural heritage, oracle bone inscriptions, Yin Ruins, Wenfeng Pagoda, Yuan Lin is its unique cultural symbols. The influence of culture on the city is inherent, these special cultures also affect everyone living here with the continuation of time, and to a certain extent, prosper the city's tourism and promote the economic development of the ancient city. 
Folklore cultural activities reflect the different activities of people living here in different seasons for a long time, most of which express the awe of nature and belief. Therefore, the protection of traditional folk cultural activities can enhance people's sense of identity and belonging to the ancient city culture, but also highlight local characteristics. Traditional commercial activities are inherited and carried forward by the people today, and most of the traditional commercial streets in the ancient city have been preserved, which is worthy of affirmation. The shortcoming is to the traditional business model by the impact of modern commerce, resulting in the loss of some characteristics, need to reflect and improve. Existing alleys, there is its own unique flavor of the market. Traditional houses and buildings scattered distribution, where residents live in downtown, but has its own quiet. People living in the ancient city seldom have the fatigue brought by the tense rhythm of life of the traditional urban people, which is particularly harmonious and harmonious with the environment of the ancient city.

\section{Renewal Strategy of Anyang Ancient City}

\subsection{Control and Planning of Ancient City Indicators}

The index control of the ancient city is mainly embodied in the control of building density, volume ratio, population capacity and green space rate, only by controlling the various indicators within a reasonable range, can the living experience of the residents in the ancient city and the overall atmosphere of the ancient city be improved accordingly on the existing basis.

The first is the control and adjustment of building density, because the ancient city of the building respectively belongs to different historical periods, because of different periods and different subject subjectivity, so there will be building area and area differences. Decreasing the density of buildings and improving the living experience also need very careful consideration, and make a scientific planning and resettlement plan. The spontaneous construction of buildings exceeding the prescribed height will be demolished until reaching a reasonable number of floors. Individual private expansion of building scope, more land outside the building scope of the demolition of buildings.

Volume ratio, that is, the total building area than the total land area, the result is too high will reduce people's living comfort, to make living comfort high, volume ratio should be reduced. Anyang ancient city itself has passed through a long history of accumulation, the city's prosperous commerce, strong market atmosphere, and convenient transportation itself has a strong attraction will attract more people to settle here, which is one of the important reasons for the high volume ratio. In addition, the fundamental reason for the high volume rate is the transmission of the original residents who have lived here for generations. In addition, the people themselves have a strong sense of belonging and responsibility, so they are more reluctant to leave the place where their ancestors have lived for generations. Correspondingly, the high volume rate is also the main reason for the high population capacity, and the volume rate is controlled within 
a certain range so as to set a threshold for the maximum population capacity. Through propaganda and incentives and other ways to guide some people to live in other areas outside the ancient city, improve the cost of living of foreign residents, can effectively reduce the population capacity.

The rate of green space can directly or indirectly affect the physical and mental health of the residents. Just completed and put into use of the Zhangde Garden to a certain extent ease the situation of less green space in the ancient city but has not been able to fundamentally improve the green space rate green space and open park construction task is arduous still need a long time evolution will be improved. In addition, many elderly people in the city need to have a centralized entertainment and leisure places, some of the valueless housing can be transformed, the construction of elderly mobile housing, for the residents of the ancient city of leisure and entertainment.

\subsection{Adjustment of Land Use Function of Ancient City}

According to the analysis of the current problems, we can determine the general direction of all kinds of land use in the future, which is mainly residential land use, the nature of cultural relics and monuments land use remains unchanged, should be preserved permanently now and in the future, appropriate increase in landscape and public facilities land use, remove and transform the nature of existing industrial land use.

Garden land includes existing ancient trees and famous trees, and the water surface of pits and ponds also has newly added public green space. The protection of ancient trees and famous trees should be delimited according to relevant regulations, and the newly built open green space should be in harmony with the ancient trees. Garden land can only be increased, not decreased. The nature of the land used by the old factories relocated can no longer be retained, the functions of the land used can be adjusted, and new buildings or buildings used by factories can be rebuilt on the existing land. The traditional form of residential land remains unchanged, but it does not mean that no changes will be made. Some of the infrastructure can be improved appropriately, so that residents can have a higher evaluation of their living experience. A series of transformation, the second people's hospital for modern functions and modern architectural form, its existence and the overall style of the ancient city is not suitable, considering the long-term development direction, it is inevitable to implement the transformation of the current architectural form, the hospital can also be considered to be built outside the ancient city of Anyang.

The main reason for the unreasonable land area of the ancient city is that the history of the building is relatively long, people's knowledge and knowledge are limited, and building materials also limit the form of the building. Therefore, some buildings have lost their due value when they are preserved, which requires us to take the essence and abandon the dregs in the process of transformation, and demolish the worthless buildings according to the actual situation, so that 
new buildings can be built in the ancient city, but to ensure that they are compatible with the original architectural style, the construction of antique streets should also be rich in changes, and restore the previous appearance to the greatest extent, reflecting the original architectural and humanistic customs.

\subsection{Protection of Historical and Cultural Blocks}

The most important point is to maintain the original architectural style and style and retain the original charm of the ancient city. The historical and cultural blocks of the ancient city of Anyang include three ancient blocks with different characteristics, namely, West Street, Cangxiang Street, Chenghuangmiao and Wenchang Pavilion. According to the planning requirements, it is divided into key protected areas and control construction areas, and the buildings in key protected areas should be treated specially, repaired on the basis of protection, with full respect for historical relics, and historical relics should not be ignored in the transformation and reconstruction of buildings with historical value, and every detail that can reflect historical characteristics should be treated with awe. The original style and features of historical blocks in the transformation and renewal of the last time or to protect the first, restore the main. Urban atmosphere can be reflected in the overall street pattern and spatial scale, in order to maintain a strong cultural atmosphere in the city, we should adjust the architectural style of incongruity. Historical and cultural blocks within the existing variety of small buildings, housing and block renovation should take into account the overall unity, healthy development.

The control of construction is mainly to limit the volume, shape, color, height and style of the building. In traditional streets and alleys, the cornice of new buildings should be within the scope of six meters, and the buildings beyond the scope should be rectified. The appearance should also be in line with the overall style and highlight the architectural characteristics different from other areas. The cornice height of new buildings that are not traditional streets and alleys should be within the scope of nine meters. Uncoordinated places can form a harmonious block environment by transforming the appearance form. Buildings with low historical value or almost non-existent can not be demolished and built without consideration and balance. After planning and agreement by the relevant departments of urban planning, appropriate reconstruction plans can be worked out and then implemented.

\subsection{Protection of Cultural Relics and Monuments}

There are many cultural relics and historic sites in the ancient city of Anyang. First of all, we should delimit corresponding cultural relics protection zones according to different cultural relics, and prohibit all activities harmful to ancient buildings and cultural relics within the protected areas. Municipal projects and real estate projects should strictly abide by the regulations in the construction process. If they persist in affecting cultural relics and historic sites, they should 
be ordered to suspend business for rectification and confiscate their rights to build. For non-man-made damage to historical sites, a restoration plan shall be formulated in accordance with the Law of the People's Republic of China on the Protection of Cultural Relics. For cultural sites under key state protection, the plan shall be submitted to the State Council for examination and approval. For all destroyed historical sites and sites to be maintained, reconstruction is not allowed or feasible. A list of cultural heritage protection shall be established, and existing cultural relics and historical sites shall be filed for record, so as to provide a basis for future restoration and preservation.

The restored historic sites can be opened as scenic spots, but they can not be transformed or misappropriated without the consent of the relevant departments. In the process of protection and renewal, the special features of the ancient city can be maintained to the greatest extent through the analysis of specific problems. The relationship between the old and the new history should be handled on the basis of the original. At the same time, the suggestions of the residents of the ancient city for urban construction should be fully adopted and their wishes should be respected. The inheritance and retention of intangible cultural heritage is also of great significance.

\subsection{Regulation of Road Traffic}

The policy of public transport priority in China [3]. Public transport priority refers to the passenger transport in the city, which is mainly based on the public transport system, supplemented by other means of transport. At present, the freedom and extensiveness of people's work and life can invisibly increase the traffic pressure in the city. Public transport can reduce the pressure of urban roads, which is convenient for life and environmental protection. On the basis of existing public transport, public transport and pedestrian traffic can be complementary to each other. Because of the narrow road environment in the ancient city itself, it is a good choice to further expand the width of the road, the ancient city road system with pedestrian street and public transport as the main part. Anyang ancient city is located in the center of Anyang City, which indirectly aggravates the traffic congestion around the ancient city. Although Wenfeng Avenue currently implements two-way lane diversion in the ancient city, to a certain extent, it alleviates traffic congestion, but the situation has not been fundamentally solved. On the basis of fully grasping the factors of the ancient city's own conditions, historical and cultural background and urban development orientation, it puts forward the overall strategic objectives that are compatible with the current development process of the ancient city.

\section{Conclusions}

The renewal of the ancient city of Anyang has a long way to go, the characteristics of the ancient city; historical and cultural connotations in the protection of the ancient city should be given priority. Through the analysis and research of 
the ancient city of Anyang, we realize that the protection and renewal of the ancient city is the product of the progress of the times and historical development. Whether the government or citizens, all shoulder the important mission. The protection of the ancient city is extremely important to the contemporary and future, and the renewal of the ancient city is to let the historical context be inherited in the renewal. The city was originally a fixed residential area with the function of commercial exchange, but through the changes of history and the development of the times, the function of the city has been gradually increased. The so-called ancient city is a city that has been preserved after continuous changes. Time and years are merciless, so the existing ancient city will encounter a series of new problems.

The protection and renewal of the ancient city need to be explored and discussed in depth; different subjects and groups have their own views and opinions, which requires an authoritative arbitrator to weigh the pros and cons of the scheme, and find out the road and direction suitable for the ancient city. The renovation plan of Qiaojia Lane and Guandai Lane, although maintaining the traditional style of the ancient city, has not taken into account the specific details, the large volume and size of the built buildings, and the inappropriate local treatment.

Ancient city transformation needs to consider many factors, such as culture, economy, social customs and habits. As urban planning is a government behavior, the transformation and renewal of ancient city also belongs to urban planning. The government should take into account the interests of all parties, and constantly strengthen its powers. The historical features of the ancient city formed in different periods are not the same, which requires us to fully investigate on the basis of serious research, better deal with the relationship between all parties, so that the historical context can be continued, out of a city with the characteristics of the times to transform the road of renewal. The protection and renewal of the ancient city of Anyang is not smooth sailing. In such a more complex environment full of temptation, city builders can stick to their original intention and the bottom line is very important. Planning drawings can not only stay on paper; feasibility and specific operability are more important. We should find a suitable way for their own development, avoid blind imitation and unrealistic pursuit of economic benefits.

In the process of protection and development of the ancient city, we should not only solve the problem of protection and development of the ancient city, but also pay attention to the relationship between protection and utilization of cultural relics. Scientific and reasonable display of cultural relics and historic sites is a kind of value display for itself and cultural dissemination for visitors. It can let more people understand the integrity of history and culture. History and culture are the soul of a city. In the protection and renewal of the ancient city, we should put history, culture, architecture and cultural relics and historic sites in the same important position. The reasonable, orderly, symbiotic and complementary relationship between modern functions and traditional buildings in 
the ancient city is the direction of our efforts for a period of time to come. To solve this problem, we should attach importance to the scientific and rational planning. The people's life and the protection of the ancient city should be both, and the state should implement the policy of "giving priority to protection and putting rescue first" for famous historical and cultural cities. The protection of the ancient city is the basis for promoting the better development of the ancient city, and the renewal is the magic weapon for the continuous success of the historical context of the city.

\section{Conflicts of Interest}

The authors declare no conflicts of interest regarding the publication of this paper.

\section{References}

[1] Zhi, J.R. (2010) Research on the Protection and Renewal of Anyang Old City. Hunan University, Changsha.

[2] Cetin, M. (2015) Evaluation of the Sustainable Tourism Potential of a Protected Area for Landscape Planning: A Case Study of the Ancient City of Pompeipolis in Kastamonu. The International Journal of Sustainable Development and World Ecology, 22, 490-495.

[3] Xie, C.Q. (2006) Circular Economy and Urban Sustainable Development. Sichuan University, Chengdu. 